\title{
AVALIAÇÃO DE UM MOTOR DE COMBUSTÃo INTERNA OPERANDO COM GÁS DE BIOMASSA.
}

\author{
R. V. Andrade ${ }^{1}$, Corrêa JR,P.S.P ${ }^{2}$, E. E. S. Lora ${ }^{3}$ \\ Universidade Federal de Itajubá (UNIFEI), Instituto de Engenharia mecânica (IEM), \\ Núcleo de Excelência em Geração Termelétrica e Distribuída (NEST). \\ E-mail para contato: $\quad$ ruben@unifei.edu.br \\ pauloccet@yahoo.com.br \\ electo@unifei.edu.br
}

\begin{abstract}
RESUMO - O projeto P\&D DE 0041 UNIFEI/CPFL/ANEEL trata da utilização de energia renovável para conversão em energia elétrica através de um sistema hibrido solar biomassa onde tecnologias como a gaseificação/motores de combustão interna, motores Stirling, e ciclos Rankine orgânicos são estudados. O trabalho em questão apresenta o resultado obtido das modificações realizadas em um motor alternativo de ignição por centelha para melhoria de seu desempenho quando se usa gás produto da gaseificação de biomassa como combustível. Foram feitas alterações na câmara de combustão do motor através da troca do pistão, bem como, no avanço da ignição. Valores anteriores as modificações para potência elétrica fornecida pelo motogerador eram de $5,6 \mathrm{~kW}$ elétricos, com as modificações realizadas e aprimoramento de operação do sistema pode-se obter valores de $6,7 \mathrm{~kW}$ elétricos.
\end{abstract}

\section{INTRODUÇÃO}

A biomassa é um recurso natural renovável com grande potencial para conversão em energia elétrica, principalmente quando se considera o aproveitamento de resíduos. No projeto P\&D 153 foi pesquisada a aplicação do gás de biomassa (gás pobre) em motores de combustão interna de ignição por centelha, com sucesso, todavia uma das modificações que poderia ter sido feita para melhoria do desempenho do motor não pode ser realizada. Essa modificação é o aumento da taxa de compressão do motor. Estudos de outros pesquisadores apontavam que seria possível operar um motor com gás de biomassa com uma taxa de compressão de 17:1 sem o aparecimento do efeito "knock", devido às características do gás como a presença de gases inertes que atuam como supressores desse efeito. Como a eficiência dos motores que operam segundo o ciclo Otto é influenciada pela taxa de compressão então operar o motor com uma elevada taxa de compressão poderia diminuir o "de-rating" apresentado quando se opera o motor com gás pobre. Levando esse fato em consideração se propôs a modificação da taxa de compressão do motor a fim de avaliar a possibilidade de operar com valores superiores a $5 \mathrm{kWe}$ que foi o valor que se obteve para uma operação continua com gás de biomassa. A modificação do avanço da ignição também foi alvo do estudo. 


\subsection{A GASEIFICAÇÃO DE BIOMASSA}

Define-se como biomassa todo material de origem orgânica animal ou vegetal, cuja energia armazenada pode ser convertida através de um processo termoquímico ou biológico. É um recurso natural, renovável e que pode ser aproveitado para conversão em energia elétrica desde que devidamente tratada.

Um dos processos para conversão da biomassa em eletricidade é através de uma rota termoquímica denominada de gaseificação. A gaseificação é o processo de conversão através do qual a biomassa é convertida em um gás combustível em reatores denominados gaseificadores onde ocorre um processo de queima em condições abaixo da estequiométrica. $\mathrm{O}$ gás produzido contém principalmente $\mathrm{CO}, \mathrm{H}_{2}$, e $\mathrm{CH}_{4}$, além de gases inertes $\mathrm{CO}_{2}$ e $\mathrm{N}_{2}$ e contaminantes como o alcatrão. O poder calorifico do gás depende do tipo de agente de gaseificação utilizado, sendo o mais comum o ar que fornece um gás com poder calorifico inferior de aproximadamente 5 $\mathrm{MJ} / \mathrm{Nm}^{3}$.

Os gaseificadores mais comuns utilizados são os de leito fixo e de leito fluidizado, sendo que os de leito fixo podem ser do tipo co-corrente, contracorrente, e fluxo cruzado. Os de leito fluidizado podem ser do tipo borbulhante e circulante. Neste trabalho é utilizado um do tipo cocorrente com duplo estágio de gaseificação.

\subsection{O CICLO OTTO}

O ciclo padrão ar Otto é um ciclo que se aproximada do ciclo de operação de um motor de combustão de ignição por centelha. Esse ciclo é composto por um processo de compressão isoentrópico, fornecimento de energia a volume constante, expansão isoentrópica e liberação de energia na forma de calor para o meio a volume constante. A eficiência do ciclo pode ser determinada pela equação 1.1, pode-se verificar analisando essa equação que quanto maior a relação de compressão maior será a eficiência do ciclo.

$$
\eta=1-\left(\frac{V_{1}}{V_{2}}\right)^{1-k}=1-\frac{1}{\left(\frac{V_{1}}{V_{2}}\right)^{k-1}}
$$

Na figura 1.1 pode ser visualizado um desenho esquemático de um conjunto cilindro pistão utilizado em motores alternativos de combustão interna. Nele é possível é possível identificar o curso do motor (s), e os pontos mortos inferior (PMI) e superior (PMS), bem como o diâmetro do cilindro, e a região que seria a câmara de combustão. Pode-se identificar ainda a vela de ignição e as válvulas de admissão e escape. O ângulo do virabrequim também é apresentado. 


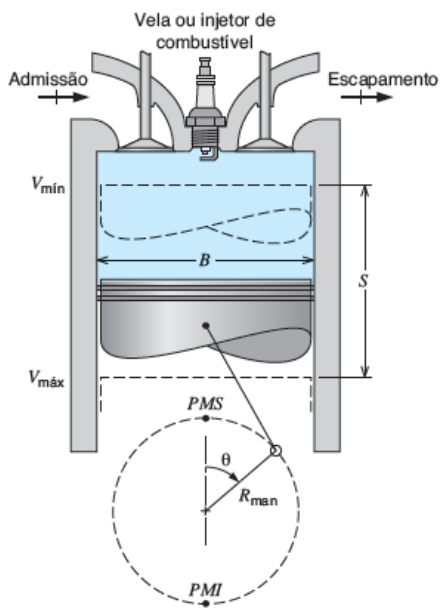

Figura 1.1 - Configuração cilindro-pistão utilizada nos motores de combustão interna (Borgnakke, 2012).

A taxa de compressão pode ser calculada pela relação entre o volume percorrido pelo embolo mais o volume da câmara de combustão pelo volume da câmara de combustão (equação $1.2)$.

$$
\mathrm{r}_{\mathrm{v}}=\frac{\mathrm{V}_{1}}{\mathrm{~V}_{2}}=\frac{\mathrm{V}_{\mathrm{s}}+\mathrm{V}_{\mathrm{CC}}}{\mathrm{V}_{\mathrm{cc}}}
$$

\subsection{O AVANÇO DA IGNIÇÃO}

O avanço da ignição de um motor ciclo Otto, refere-se ao momento do centelhamento da vela com relação ao posicionamento do pistão ao longo do curso. Esse posicionamento é relacionado com o ângulo do virabrequim em graus. Quando se fala, por exemplo, que o avanço de ignição de um motor é de $10^{\circ}$, quer dizer que a ignição está ocorrendo $10^{\circ}$ antes do pistão alcançar o ponto motor superior. Esse avanço do motor é necessário para que a queima do combustível se processe dentro da câmara de combustão. Adequado este parâmetro permite obter um maior rendimento. O gráfico da figura 1.2 apresenta o torque de um motor com relação ao avanço da ignição. Se o avanço for muito elevado, a pressão máxima no cilindro será muito antes do pistão atingir o PMS e se for muito atrasado a pressão máxima será tardia reduzindo o trabalho de expansão, ocasionando também elevada temperatura dos gases de descarga.

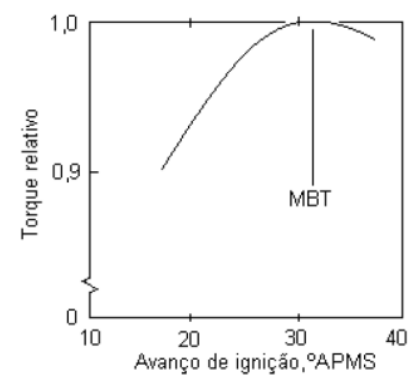

Figura 1.2 - Ciclo indicado em função do ângulo do virabrequim Heywood (1995 apud Amorim, 2005) 


\section{EFEITO KNOCK}

Valores de taxas de compressão elevados podem ocasionar o efeito "knock", que é descrito como sendo a ignição de determinados pontos da mistura em locais diferentes da frente de chama devido ao aumento da temperatura acima do ponto inflamabilidade da mistura ocasionando ondas de pressão indesejadas que se chocam contra as paredes do cilindro e com a frente de chama.

A combustão ocorre à velocidade subsônica (deflagração) a propagação das ondas de ignição indesejadas que ocasionam o "knock" ocorre a velocidades sônicas relativas aos gases de combustão. A combustão normal gera ondas de pressão que viajam a velocidade do som, sendo sua velocidade superior à velocidade de frente de chama. No "knock" as velocidades de frente de chama e de propagação da pressão são iguais, o que ocasiona o aumento brutal de pressão local e ondas de pressão elevadas (Martins, 2013)". Segundo Sridhar (2013), é possível operar um motor com gás de biomassa ou gás pobre com valores de taxa ade compressão de até 17:1, sem o aparecimento do efeito "knock". Na figura pode ser vista a influencia do avanço da ignição para operação de um motor utilizando gás pobre com uma taxa de compressão de 17:1.

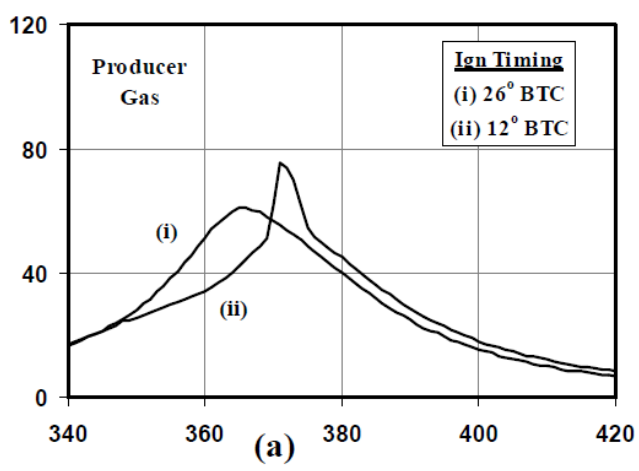

Figura 2.1 - Operação de motor com taxa de compressão de 17:1, usando como combustível gás

\section{O GASEIFICADOR} pobre (Sridhar, 2013)

Trata-se de um reator do tipo co-corrente com duplo estágio de gaseificação, onde o gás produzido se movimenta no mesmo sentido do combustível. Diferentes dos gaseificadores convencionais co-correntes, no duplo estágio há o fornecimento do agente de gaseificação em duas regiões, sendo uma na região de combustão e outra onde seria a região de pirólise. Essa configuração possibilita uma redução do teor de alcatrão presente no gás produzido. A biomassa utilizada como combustível foi o eucalipto. A tabela 1 mostra as características nominais do equipamento.

O mesmo foi operado tendo em vista observar algumas das modificações realizadas para se obter a melhoria de seu funcionamento.

Um dos pontos a se verificar seria a presença em excesso de umidade que chegava ao motor. Para resolver esse problema foram colocados dois equipamentos para reter a umidade. 


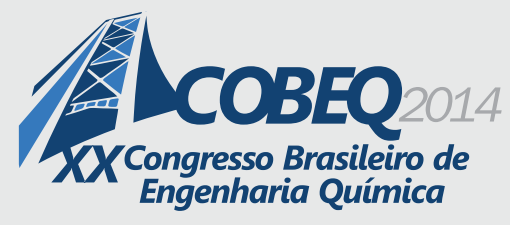

19 a 22 de outubro de 2014

Florianópolis/SC

Observou-se que há necessidade de retirada constante da umidade armazenada, caso contrário, a umidade se acumula e pode chegar até o filtro fazendo com que o mesmo fique úmido bloqueando completamente o gás produzido, prejudicando assim o funcionamento do sistema. Pequena quantidade de umidade ainda foi observada no segundo filtro, mas sem prejuízo ao funcionamento do sistema. Essa umidade pode ser relacionada não só a da biomassa, mas algum percentual que possa ser arrastada do reservatório pulmão.

Tabela 1. Características e parâmetros nominais do gaseificador.

\begin{tabular}{|l|c|c|}
\hline \multicolumn{1}{|c|}{ Parâmetro } & Unidade & Valor \\
\hline Diâmetro externo & $\mathrm{m}$ & 50 \\
\hline Diâmetro interno & $\mathrm{cm}$ & 30 \\
\hline Potência térmica & $\mathrm{kWt}$ & 50 \\
\hline Consumo de biomassa (base seca) & $\mathrm{kg} / \mathrm{h}$ & 10 \\
\hline Consumo de biomassa (base úmida) & $\mathrm{kg} / \mathrm{h}$ & 12 \\
\hline Dimensões da biomassa utilizada & $\mathrm{m}$ & $0,02-0,06$ \\
\hline Fator de ar & - & 0,35 \\
\hline
\end{tabular}

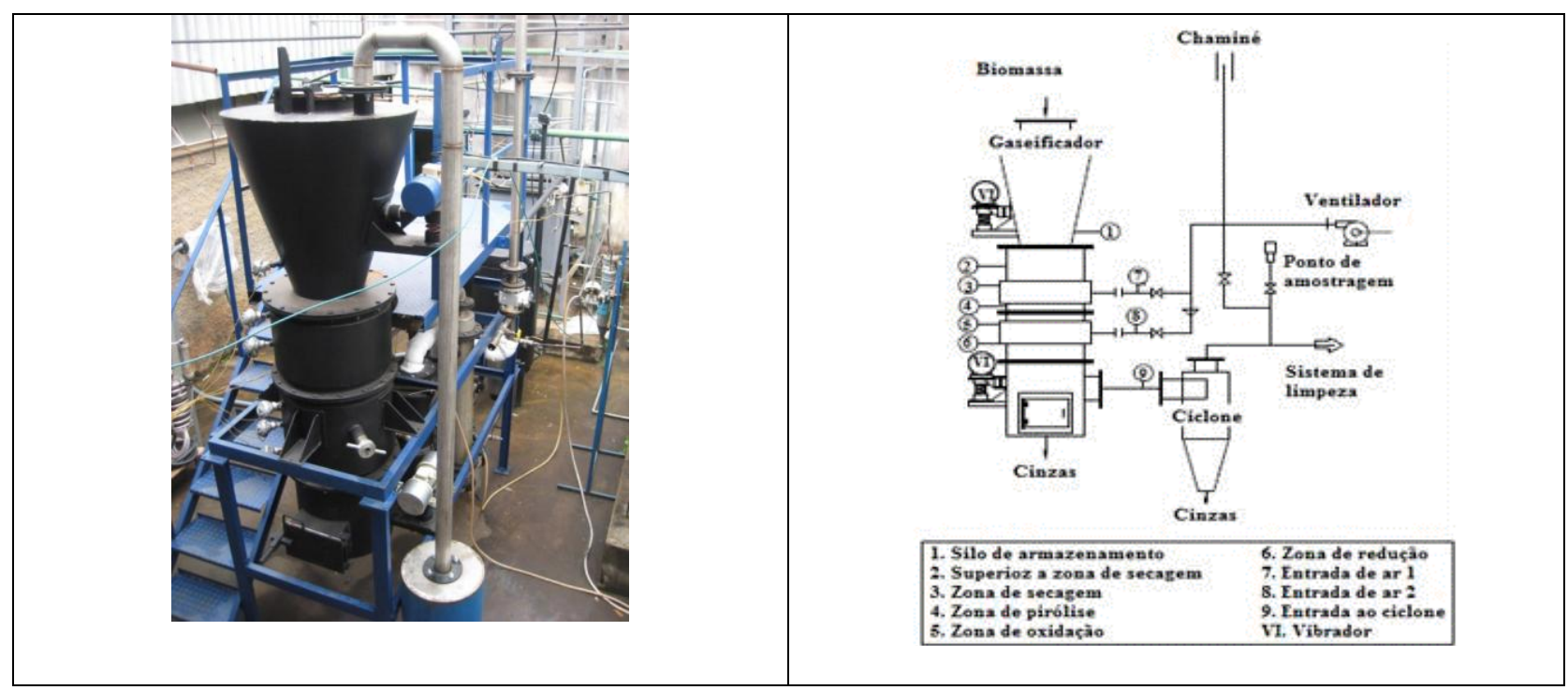

Figura 3. 1 - Gaseificador de duplo estágio

O reservatório pulmão ainda tem um funcionamento inadequado travando sempre no início da operação, podendo ter apresentado problemas construtivos, que devem ser verificados. Todavia, pode operar sempre com algum ajuste inicial.

O gaseificador (figura 3.1) foi operado apenas no primeiro estágio, tendo funcionado adequadamente, porém percebeu-se a presença de um material oxidante que chegou a válvula borboleta da admissão do motor, provocando o seu travamento. Não foi constatada a presença visual de alcatrão, nem cheiro característico na entrada do motor durante o período de testes. 


\section{METODOLOGIA}

Inicialmente o motor foi acionado com GLP sem nenhuma modificação para verificar se o seu funcionamento estava adequado, foi fornecido carga, tendo operado com valores de $10 \mathrm{kWe}$. Realizou-se a desmontagem do mesmo para se efetivar a troca dos pistões, que possibilitariam a modificação da taxa de compressão. Na figura 4.1, pode-se visualizar o motor ainda com os pistões antigos.
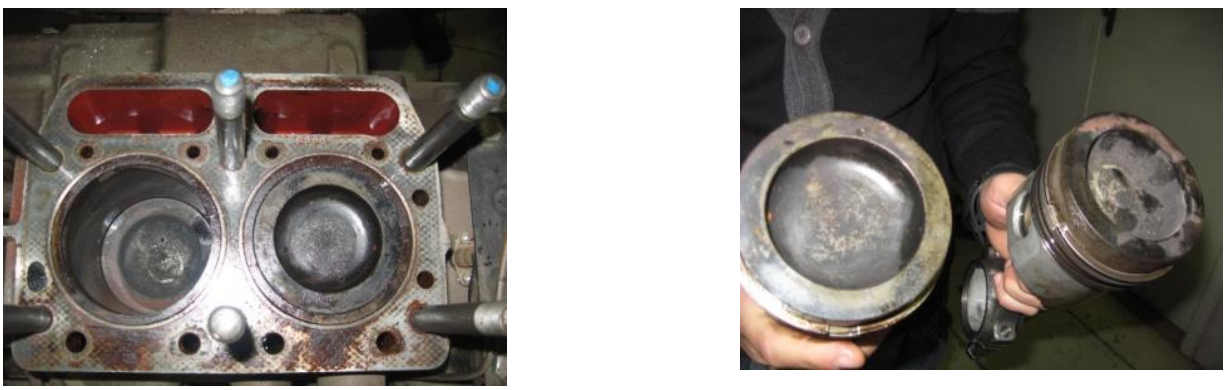

Figura 4.1 - Foto do motor aberto sem o cabeçote com os pistões antigos

Foi realizada a modificação dos êmbolos para que se pudesse alterar assim a taxa de compressão do motor. O novo êmbolo tem a parte superior lisa sem concavidade como pode ser verificado na figura 4.2. O novo pistão permite a operação com uma taxa de compressão mais elevada que segundo o fabricante é de 13:1. O diâmetro do cilindro $90 \mathrm{~mm}$ com um curso de 90 mm. Essa taxa de compressão estava limitada pelo espaço necessário à vela e ao curso do motor. Após a desmontagem do motor e posterior limpeza foi realizada a montagem do mesmo com os pistões novos (figura 4.3). Na figura 4.4 pode ser visualizado o motor já com os pistões novos.

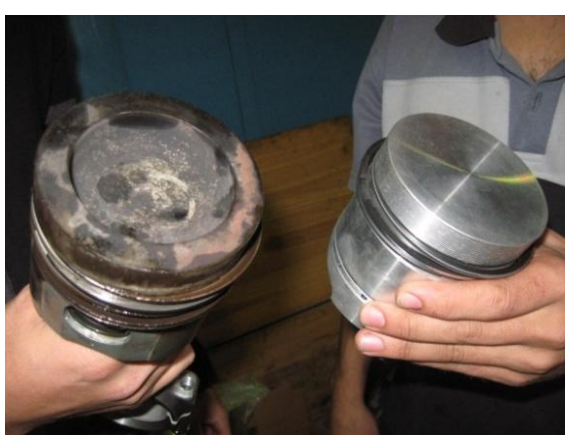

Figura 4.2 - Comparação entre os pistões.

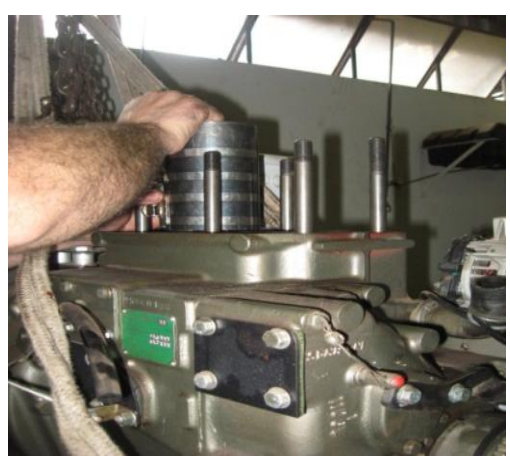

Figura 4.3 - Montagens dos pistões. 

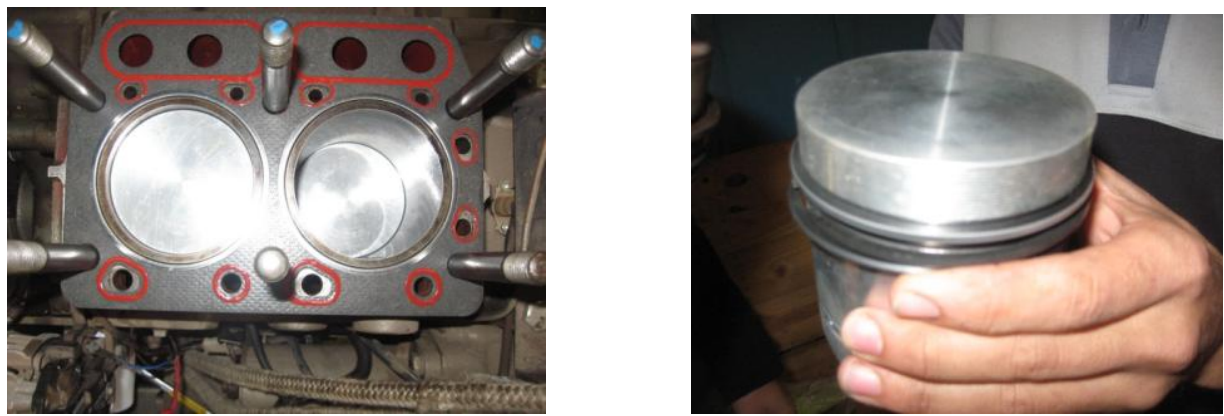

Figura 6.4 - Foto do motor com os novos pistões.

Após a montagem dos pistões, foi necessário colocar o motor no ponto e calibrar as molas do balancim. A seguir foram montados todos os periféricos e foi feita a reposição do óleo e da água de arrefecimento do motor. Posteriormente foi realizado o ajuste do avanço da ignição do motor com auxilio do software que foi fornecido pela ERBR. Esse ajuste pode ser conferido com a utilização da pistola estroboscópica.

Para avaliação preliminar do desempenho do conjunto gaseificador/motogerador optou-se por operar o gaseificador apenas com um estágio de fornecimento de ar que seria a pior condição em termos de qualidade do gás considerando o conteúdo de alcatrão, o que permitiria avaliar se o sistema de limpeza estava funcionando.

Procurou-se ajustar a operação do gaseificador de forma que ele pudesse fornecer o máximo de energia no gás produzido. Inicialmente o gaseificador foi operado até que o mesmo atingisse as condições ideais de funcionamento fornecendo um gás que pudesse ser enviado ao motor, até atingir esse ponto o gás gerado é incinerado. Quando o gás estava adequado para fornecimento ao motor ele é direcionado para o sistema de limpeza e em seguida ao reservatório pulmão, sendo enviado ao motor.

É necessário que o motor esteja previamente aquecido para um melhor funcionamento com o gás de biomassa. Após ter partido e sido aquecido, o GLP pode ser gradativamente substituído pelo gás pobre até sua completa substituição. Foi fornecida carga ao motor através de uma bancada até a potência que ele poderia suprir com funcionamento contínuo. O processo é então avaliado após o sistema ter entrado em regime quando são lidas as grandezas, tendo-se dados maior atenção ao valor da potência elétrica fornecida. Foi feito o ajuste do avanço de ignição para verificara melhor condição de operação do motor.

\section{RESULTADOS}

Tendo-se alterado o valor da taxa de compressão o motor foi operado com gás de biomassa, obtendo-se novamente um valor de aproximadamente $5 \mathrm{kWe}$, que foi o mesmo obtido em testes anteriores. Partiu-se, então, para a modificação do avanço de ignição, onde se buscou variar o mesmo desde $10^{\circ}$ APMS até $30^{\circ}$ APMS, tendo-se obtido o melhor valor para $24^{\circ}$ APMS, com valores de $6,75 \mathrm{kWe}$ com operação continua como pode ser constatado na figura 5.1. Esse valor é adequado à operação do sistema de integração já que havia se previsto apenas fornecer 6 kWe. Durante a operação não foram verificados ruídos característicos da presença do efeito 
"knock", porém apenas com a instalação de equipamento adequado para monitorar as variações de pressões no interior da câmara de combustão isso poderá ser confirmado. A potência obtida é também influenciada, obviamente, pelo gás entregue pelo gaseificador. O poder calorifico do gás esteve na faixa de $5 \mathrm{MJ} / \mathrm{Nm}^{3}$, com percentuais em volume de $\mathrm{CO}, \mathrm{H}_{2}$ e $\mathrm{CH}_{4}$ de $22 \%$, 17 e 1,9\%, respectivamente, como pode ser verificado na figura 5.2.
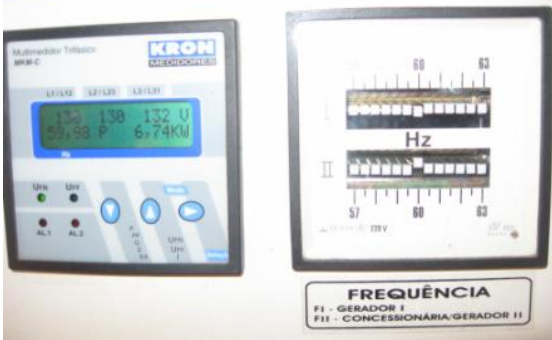

Figura 5.1 - Simulação de carga

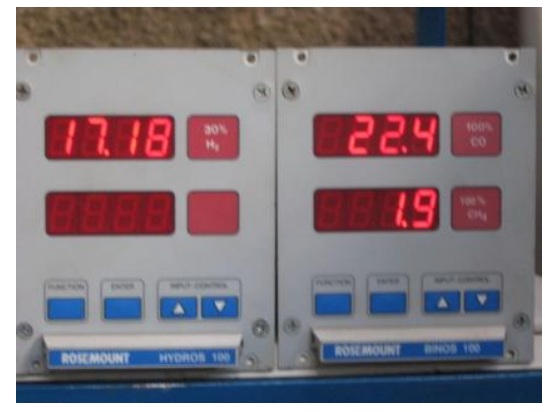

Figura 5.2 - analisadores contínuos de gases mostrando a fração volumétrica de $\mathrm{H}_{2}, \mathrm{CO}$ e $\mathrm{CH}_{4}$

\section{CONCLUSÕES}

Observou-se a presença de muita umidade no gás gerado e constatou-se a presença de alcatrão no gás antes do sistema de limpeza, essa análise deverá ser mais criteriosamente realizada através de testes de longa duração. O valor do alcatrão apresentado não foi contabilizado, todavia poderá ser reduzido com o gaseificador operando com duplo estágio. O objetivo proposto a partir das modificações do motor foi alcançado, tendo operado a 6,75 kWe de forma continua sem a detecção do efeito "knock", todavia isso só poderá ser efetivamente constatado a partir da instalação de equipamento especifico que permita a monitoração da pressão no interior da câmara de combustão.

\section{AGRADECIMENTOS}

Os autores desejam agradecer a CAPES, FAPEMIG e CPFL/ANELL pela sua colaboração e o apoio financeiro no desenvolvimento deste trabalho.

\section{REFERENCIAS BIBLIOGRAFICAS}

AMORIM, R. J. Análise do aumento da razão volumétrica de compressão de um motor flexível multicombustível visando melhoria de desempenho. Dissertação (Mestrado em Eng. Mecânica). Universidade Federal de Minas Gerais. Belo Horizonte, Minas Gerias, 2005.

MARTINS, J. Motores de Combustão Interna. 4a. Ed. Porto: Publindústria, 2013.

SRIDHAR, G.; Yarasu, R. B. Facts about procucer gas engine, paths to sustainable energy. Disponível em <http://www.intechopen.com/books/paths-to-sustainable-energy/facts-about-producer-gas-engine>. Acesso em: agosto, 2013.

BORGNAKKE, C.; SONNTAG, R. E. Fundamentos da Termodinâmica. Tradução da $7^{\mathrm{a}}$. Ed. São Paulo: Blucher, 2012. 